\title{
ПРОБЛЕМА ПЕРЕВОДА РУССКИХ ПОСЛОВИЦ НА КИТАЙСКИЙ ЯЗЫК (НА МАТЕРИАЛЕ КЛАССИЧЕСКИХ ПРОИЗВЕДЕНИЙ)
}

\author{
Ван Мэн \\ Российский государственный гуманитарный университет
}

\section{THE PROBLEM OF TRANSLATING RUSSIAN PROVERBS INTO CHINESE (ON THE EXAMPLE OF CLASSICAL WORKS)}

\author{
Wang Meng \\ Russian State University For The Humanities
}

\begin{abstract}
Аннотация: в статье рассмотрены проблемы перевода русских пословиц на китайский. Выявлены основные особенности пословии (общеизвестность, образность, рифма и т. д.), которые вызывают определенные трудности при поиске аналога в переводе. Каждая нация имеет свои культурные традиции, мышление, ценности, которые отражаются в пословицах. Толкование пословии в словарях ограничено их семантикой, передает лишь общий смысл в отвлечении от типовых ситуаций их использования. При переводе важно анализировать прагматические свойства пословии, определить их функции и роль в дискурсе, особенно в диалогической речи. Цель статьи заключается в попытке выявить оптимальные способы передачи значения, дискурсивных функиий послович и сохранения их образности в прочессе перевода. В статье рассматриваются и анализируются пять способов перевода пословии В. С. Виноградова: полный эквивалент, частичный эквивалент, калькирование, псевдосоответствие и описательный перевод. Анализ китайских аналогов русских пословии, конкретных переводческих решений проводится на материале перевода диалогических фрагментов из художественных произведений русской классики. В результате исследования делается вывод о том, что универсального способа перевода пословии не существует. Адекватный перевод требует не только передачи значения пословицы, но и сохранения ее прагматических характеристик. Оптимальным считается перевод пословицы пословицей с тем же значением и сохранением образности, однако при отсутствии точных аналогов в языке перевода приходится жертвовать той или иной прагматической характеристикой. В результате проведенного в статье анализа мы пришли к выводу о том, что самым ненадежным способом перевода является дословныи перевод. При поиске подходящего аналога необходимо рассмотреть все параметры пословии, учесть семантические, культурологические и прагматические особенности таких культурно и фразеологически обусловленных языковых единиц.
\end{abstract}

Ключевые слова: пословищы, способы перевода, прагматика, контекст, китайские эквиваленты.

\begin{abstract}
Russian Proverbs into Chinese. The main features of proverbs that cause certain difficulties in finding an analog in translation are revealed (common knowledge, imagery, rhyme, etc.). Each nation has its own cultural traditions, values and way of thinking, which are reflected in proverbs. The interpretation of proverbs in dictionaries is limited by their semantics, it only conveys the general meaning in distraction from the typical situations of their use. When translating, it is important to analyze the pragmatic properties of proverbs, determine their functions and role in discourse, especially in dialogic speech. The purpose of the article is to try to identify the best ways to convey the meaning and discursive functions of proverbs and preserve their imagery in the translation process. The article discusses and analyzes V.S. Vinogradov's five ways of translating proverbs: full equivalent, partial equivalent, calculus, pseudo-correspondence, and descriptive translation. Russian proverbs 'Chinese analogues and specific translation solutions are based on the analysis of dialogical fragments from Russian classical works of art. The study concludes that there is no universal way to translate proverbs. Adequate translation requires not only transmitting the meaning of the proverb, but
\end{abstract}

(C) Ван Мэн, 2020

Контент доступен под лицензией Creative Commons Attribution 4.0 License.

The content is available under Creative Commons Attribution 4.0 License. 
also preserving its pragmatic characteristics. An optimal translation of a proverb is considered to be a proverb with the same meaning and preservation of imagery, but in the absence of exact analogues in the translation language, one or another pragmatic characteristic has to be sacrificed. As a result, we came to the conclusion that the most unreliable method of translation is literal translation. When searching for a suitable analog, it is necessary to consider all the parameters of proverbs, take into account the semantic, cultural and pragmatic features of such culturally and phraseologically determined language units.

Key words: proverbs, translation methods, pragmatics, context, Chinese equivalents.

\section{Введение}

Пословицы представляют собой краткие образные изречения, которые содержат в себе человеческий опыт, отражают общенародную оценку типичных ситуаций жизни. За каждой из пословиц стоит бесспорный авторитет поколений, в нем передается смысл «они говорят», а не «я говорю» [1]. Они относятся к фразеологии, в состав которой включают еще фразеологизмы, поговорки и т. д. В отличие от фразеологизмов, которые являются эквивалентами слов или словосочетаний (Кот наплакал - мало), и поговорок, которые представляют собой словосочетания или краткие фразы, описывающие конкретную ситуацию или объект (Вот тебе, бабушка, и Юрьев день - говорит о неожиданном огорчении), пословицы это устойчивые, законченные фразы, которые претендуют на безусловную истину, аксиоматичность. В работе «Язык и культура» Е. М. Верещагина, В. Г. Костомарова отмечается, что пословицы имеют директивную функцию [2]. То есть они используются в речи для того, чтобы воздействовать на собеседника. Например, «Слово не воробей, вылетит - не поймаешь» предупреждает человека, что не нужно говорить необдуманные слова или осуждать за сказанное. При этом пословицы часто образны и содержат важный национально-культурный компонент. Ввиду этих особенностей их перевод несет в себе определенные трудности.

К переводу как виду человеческой деятельности лингвисты подходят по-разному. П. В. Рыбин определяет перевод как «перевыражение» текста языка-источника языковыми средствами языка перевода [3]. Похожим образом определяет перевод Л. С. Бархударов: для него это процесс преобразования текста языка-источника в текст языка перевода при неизменности плана содержания [4]. В. Вильс считает, что смысл и стиль исходного текста должны быть полностью отражены в переводе так, чтобы переведенное художественное произведение произвело такое же сильное впечатление на читателя, как и оригинал [5]. Таким образом, в теории переводчику нужно не только передать смысл переводимого текста, но и обеспечить передачу информации во всех деталях и атмосферу оригинала, выявить ситуации общения и другие внеязыковые факторы в переводимом тексте. Но на практике это получается далеко не всегда, и перевод- чику приходится чем-то жертвовать (образами, деталями и т. д.). В данной статье мы рассмотрим, как минимизируются потери при переводе русских пословиц на китайский язык.

Существуют разные способы перевода пословиц. По мнению В. С. Виноградова, они делятся на пять видов: полный эквивалент, частичный эквивалент, калькирование, псевдосоответствие и описательный перевод [6].

Полный эквивалент применяется, когда пословицы в двух языках равнозначны по смыслу, функциям и стилю. К частичным эквивалентам относятся случаи, когда пословицы в разных языках передают одинаковое значение и имеют близкую стилистическую характеристику, однако имеют различия в образном ряде. Оба способа являются самыми распространенными в переводе пословиц, так как большинство пословиц образны, рифмованы и общеизвестны. Образность пословиц - это важная художественная функция, обладающая воздействующей силой, поэтому перевод пословицы пословицей позволяет максимально передать смысл, стиль, атмосферу речи. Но при переводе с помощью частичного эквивалента образ часто теряется. Например, русская пословица «без дымма огня не бывает» и ее китайский эквивалент «без ветра волны не бывает». Обе пословицы говорят о том, что у всего есть свои причины. Но в переводе русской пословицы на китайский теряются образы «дымм» и «огонь». Зато читателям легче понять текст с помощью уже знакомой пословицы своего языка. При этом чтобы минимизировать потерю образа, можно использовать культурный комментарий внизу страницы.

В ряде случаев пословицы имеют несколько соответствующих эквивалентов в другом языке. Их значения или стиль близки, но ситуации употребления отличаются. В таком случае для переводчика важно выбрать самый подходящий вариант, учитывая реальный контекст.

Калькирование, псевдосоответствие и описательный перевод используются, когда пословицы содержат непереводимые образы и не имеют соответствующего эквивалента в другом языке. Калькирование (дословный перевод) позволяет сохранить образы. Однако при нем теряется общеизвестность и затрудняется интерпретация переносного значения пословицы. Особенно это очевидно, когда в тексте встре- 
чаются усеченные формы пословиц. Как доказано в эксперименте Г. Л. Пермякова, для носителя языка всегда легко понять то, о чем идет речь, даже видя пословицы в неполном виде [7]. Но если переводчик не поймет, что использована только часть пословицы, и будет переводить эту часть дословно, это может вызвать непонимание у читателя.

При описательном переводе прежде всего нужно учитывать толкование пословицы. Например, пословица «Не все коту масленицау». Масленица - это восточнославянский традиционный праздник, во время которого провожают зиму и встречают весну. Эта пословица означает, что все хорошее когда-нибудь кончается. Перевод пословицы должен основываться именно на этом значении.

Базового значения пословицы для выявления ее языковых возможностей недостаточно, необходимо анализировать типовые контексты и выявлять ее прагматическое значение. А. А. Крикманн полагает, что значение пословицы как письменно зафиксированного текста является лишь семантическим потенциалом, а окончательное значение зависит от конкретных ситуаций в коммуникации [8]. В словарях паремий толкование пословиц часто абстрактно, обобщенно и универсально. Она как нравоучение, совет или предупреждение направляется на всех людей. По мнению О. Е. Фроловой, для нее также характерна антропоцентричность и ситуативность [9]. В диалогической речи она описывает конкретное событие, адресована определенному лицу. При этом она может приобретать новые прагматические значения, которые не описаны в словарных статьях. В таком случае в переводе недостаточно передать семантическое значение пословицы, нужно выяснить ее прагматические свойства и функции в диалогах людей.

В работе И. А. Шаронова пословицы были рассмотрены с точки зрения дискурсивно-прагматического аспекта [10]. Дискурсивный анализ представляет собой одно из направлений исследования коммуникации. Он включает в себя следующие основные элементы: определенный контекст, время и место общения, состав участников, речевые действия между ними. Дискурсивный анализ отвечает на вопросы о том, какое намерение носит речь говорящего, как происходит речевое взаимодействие между репликами [11]. Пословицы как дискурсивные единицы в диалогическом тексте занимают особое место. По словам О. А. Леонтович, пословицы обладают иллокутивной силой, которая выражает цель говорящего и воздействует на собеседника [12]. Наиболее часто они используются как аргумент при том или ином речевом акте: побуждении к действию, принятии решения, объяснении своего поступка в прошлом и т. д. Поскольку пословицы представляют собой общеизвестные выражения, за ними стоит авторитет поколений, люди часто аргументируют свое мнение пословицами, чтобы убедить собеседника и не вызвать конфликта. Кроме того, пословицы могут употребляться как косвенный речевой акт, обычно в диалоге в качестве ответа, (отказа, оправдания, утешения, подбадривания и т. д.). В функции косвенного речевого акта пословицы соединяют в себе одновременно и речевое действие, и его убеждающую аргументацию (см. об этом подробнее в [13]).

Рассмотрим в качестве примера использования пословицу «Куй железо, пока горячо», которая в словаре В. П. Жукова трактуется так: «Торопись делать что-л., пока есть возможности, благоприятные условия и т. п.; пользуйся моментом» [14]. Из толкования единиц в словаре следует, что пословица употреблена для описания события будущего времени и адресована 2-му лицу (см. пример 1).

(1) Кузьма поерзал на стуле, решился: - Я, Евгений Николаевич, по делу к тебе тут по одному пришел. - По делу? - Евгений Николаевич, настороживиись, сел за стол. - Ну, так давай говори. Дело есть дело, его решать надо. Как говорят, куй железо, пока горячо. (В. Распутин. Деньги для Марии)

В диалоге говорящий побуждает собеседника начать речь (давай говори), а пословицу использует в качестве аргумента, поддерживающего побудительный акт. Однако контекст будущего времени и 2-го лица - не единственно возможный для использования пословицы. В контексте обсуждения прошедших событий пословица употребляется с иной целью - как оправдание своего поступка, принятого ранее решения (см. пример 2).

(2) - Зачем же вы так торопились начинать лекиии? Подготовились бы хорошенько! - заметила я Слепцову. - Надо было торопиться, - ответил он, - если бы отложить начало лекиий, то одушевление прошло бы, и тогда, пожалуй, они не удались бы; есть пословица: куй железо-пока горячо! (А. Я. Панаева. Воспоминания)

Учет прагматических значений, которые не отражаются в толкованиях, также может оказаться важным при переводе.

Итак, при переводе пословиц нужно учитывать сильные стороны каждого из вышеперечисленных способов в зависимости от каждого конкретного случая.

Далее мы проанализируем перевод русских пословиц на китайский в диалогах на материале классических произведений, выявим проблемы в их переводе и предложим при помощи вышеуказанных способов наиболее оптимальный вариант. Будут рассмотрены несколько русских пословиц:

1) пословицы, имеющие полностью совпадающие единицы в китайском языке (Век живи, век учись); 
2) пословицы, имеющие частично совпадающие единицы в китайском языке (Не сули журавля в небе, а дай синицу в руки; Под лежачий камень вода не потечет; Волков бояться, в лес не ходить; Что посеешь, по и пожнешь);

3) пословицы, которые не имеют эквивалентов в китайском языке (Любишь кататься, люби и саночки возить).

\section{Анализ русских пословиц, имеющих полный эквивалент в китайском языке}

Век живи, век учись.

Толкование: учению, познанию нет пределов [15].

Прагматика пословицы, как показывает собранная база примеров использования пословицы, связана с признанием говорящим своей ошибки, незнания чего-л. и готовностью учиться на своих ошибках.

Эта пословица имеет полный эквивалент в китайском языке и по смыслу, и по форме (предложение с двойным императивом): 活到老, 学到老 (дословно: «живи до старости, учись до старости»). Она используется в такой же ситуации, как русская пословица «век живи, век учись».

Рассмотрим, как переводят данную пословицу в нестандартных коммуникативных ситуациях и можно ли ее заменить эквивалентом в китайском языке.

(1) - Нет, - перебила его графиня Лидия Ивановна. - Есть предел всему. Я понимаю безнравственность, <..> - Но я не понимаю жестокости, к кому же? К вам! Как оставаться в том городе, где вы? Нет, век жсиви, век учись. И я учусь понимать вашу высоту и ее низость. (Л. Толстой, Анна Каренина)

В данном диалоге пословица «век живи, век учись» используется как вежливое псевдопризнание своего непонимания, за которым стоит раздражение.

“但是我可不了解残酷; 而且是对谁呢? 是对 您！她怎么可以留在您所在的城市里? 不, 活到老, 学到老。我可学会理解您的崇高和她的卑下了。” (https://www.sogou.com/link?url=dob0bgh2ekjriy6seybcicdfrtzxejgeqwkybw_fvr26fdhcnbxemyyutg79kv3 0eocyna0sxaswncuui_9c1noi_u0be2lundfbn6edcabo8a 0ljvrrjbp1pfileof6rgemxvs7q)

Прагматический компонент - раздражение говорящего - находит выражение в контексте. Поэтому в варианте китайского перевода используется полный эквивалент “活到老, 学到老” (дословно: «живи до старости, учись до старости»).

(2) - Немедленно спать, - решил он, осмотрев, по возможности, пациента, - а на ночь принять бы одну штучку. Примете? Я еще давеча заготовил... порочочек один. - Хоть два, -отвечал Раскольников. Порошок был тут же принят. - Это очень хорошо, что ты сам его поведешь, - заметил Зосимов Разумихину; - что завтра будет, увидим, а сегодня очень даже недурно: значительная перемена с давешнего. Век жсиви, век учись... (Ф. Достоевский, Преступление и наказание)

В данном диалоге доктор очень обрадовался, что его неочевидный рецепт подействовал и состояние его пациента улучшилось. Пословица используется в контексте приятного удивления.

“明天怎么样, 咱们到明天再看，今天却甚至很不 错：比不久前有了明显的好转。活到老, 学到老 呀...” (https://www.xingyueboke.com/zuiyufa/)

В китайском переводе была использована та же китайская пословица “活到老, 学到老” (дословно: «живи до старости, учись до старости»). С добавлением иерогифа 呀, который является знаком удивления в китайском языке. Таким образом, переводчику удается передать не только значение пословицы, но и эмоциональное состояние говорящего.

\section{Анализ русских пословиц, имеющих частичный эквивалент в китайском языке}

При сопоставлении паремий русского и китайского языков можно заметить, что многие русские пословицы имеют неточные эквиваленты в китайском языке. Рус. «у семи нянек и дитя без глаза»- кит. «у трех монахов нет воды для питья»; Рус. «тише едешь, дальше будешь» - кит. «если гонишься за быстротой - не догонишь»; Рус. «Москва не сразу строилась» - кит. «метровый лед не в один день образуется» и т. д. Несмотря на различные компоненты, эти пословичные изречения семантически близки и употребляются в одних и тех же коммуникативных ситуациях. В таком случае предпочитают переводить пословицу эквивалентом в другом языке.

Некоторые пословицы имеют более одного пословичного варианта в другом языке. Такие варианты могут быть синонимичны, но различаться с точки зрения прагматики. Например, рус. «яблоко от яблони недалеко падает» говорит о сходстве детей и родителей. Ее часто используют с осуждением, т. е. в детях повторяются пороки их родителей. В китайском языке можно найти три синонимичных пословицы «каков отец, таков и сын»; «дракон рождает дракона, феникс рождает феникса, сын крысы умеет прогрызать дыры»; «когда верхняя балка согнута, нижние тоже искривляются». Среди всех пословиц первые две имеют положительное значение, часто используются как похвала. А последняя употребляется с осуждением, она описывает не только отношения между родителями и детьми, но и отношения начальников и служащих. В переводе нужно выбирать самый подходящий эквивалент не только с точки зрения семантики, но и с точки зрения прагматики.

Рассмотрим 4 пословицы из известных русских произведений и их китайский перевод. 
Пословицы делятся на две группы: 1) у первых 3 пословиц лишь один эквивалент в китайском языке; 2) у последней пословицы - 3 эквивалента. Рассмотрим проблемы передачи этих единиц в китайском переводе и предложим самый подходящий, с нашей точки зрения, вариант.

\section{Пословицьы, которые имеют один частичный эквивалент в китайском языке}

Не сули журавля в небе, а дай синицу в руки.

Толкование: Лучше иметь хоть что-л. в данный момент, чем лишь надеяться на лучшее, большее [14, c. 222].

Китайский аналог:一乌在手, 胜过二乌在林 (дословный перевод: «Лучше одна птица в руке, чем две в лесу»).

Обе пословицы говорят о том, что лучше довольствоваться малым сейчас, чем думать о большем, лучшем, но труднодостижимом.

Волков бояться - в лес не ходить.

Толкование: Если страшиться предстоящих трудностей, опасностей, то нечего и браться за дело [14, c. 71].

Китайский аналог:不入虎穴, 焉得虎子 (дословный перевод: «Не забравшись в логово тигра, не поймаешь тигренка»).

Под лежачий камень вода не потечет.

Толкование: Если ничего не предпринимать, дело не сдвинется с места, ничто не изменится. Говорится тогда, когда кто-л. бездеятелен, не хочет сам о себе позаботиться и т. п. [14, с. 256].

Китайский аналог: 路不走不到, 钟不打不响 (дословный перевод: «По дороге не пойдешь - не дойдешь, в колокол не ударишь - не зазвенит»).

Братья прочли, что было написано, и меньшой сказал: - Давай пойдем вместе. Может быть, мы перепльвем эту реку, донесем медвежат до дому и вместе найдем счастие. Тогда стариий сказал: Я не пойду в лес за медвежатами и тебе не советую. < .. >. «Не сули жсуравля в небе, а дай синицу в руки». А меньшой сказал: - А я сльхал: «Волков бояться в лес не ходить"; да еще: "Под лежачий камень вода не потечет». По мне, надо идти. (Л. Толстой, сказка «Два брата»)

哥哥说：“俗话说，想吃大的却丢了小的；又 说, 莫想天上鸟, 喂好笼中雀。”

弟弟说：“我也听到过这样的俗话, 怕狼就别进 树林; 还说, 躺着的石头下面水也流不过去。我觉得 应该去。” (http://www.dushu369.com/tonghua/ HTML/84653.html)

В данном контексте употреблены три пословицы.

Первая пословица «Не сули журавля в небе, а дай синицу в руки». В ней использована метафора и сравнение. Синица символизирует что-то маленькое, а журавль ассоциируется с чем-то большим и хорошим. Смысл данной пословицы заключается в том, что лучше действительно ценить то, что у тебя есть, чем надеяться на то, что недостижимо. У данной пословицы есть китайский аналог «лучше одна птицза в руке, чем две в лесу». Но в переводе использован не эквивалент, а способ «псевдопословичного» соответствия, т. е. переводчик придумал новую пословицу на основе оригинала, сохраняя образы «синица» и «журавль». Таким образом, она была переведена «Не думай о журавле в небе, а хорошо корми синицу в клетке». На наш взгляд, предложенный перевод максимально передал значение, стиль и ситуацию употребления пословицы. Во-первых, у них есть одинаковая конструкция синтаксиса, обе пословицы с двойным императивным глаголом. Во-вторых, в пословице остались образы, компоненты культуры хорошо переданы. А китайский аналог немного уступает предложенному переводу из-за того, что слова «синица» и «журавль» заменены одним обобщенным названием «птицы».

Вторая пословица «Волков бояться - в лес не ходить» говорит о том, что не стоит бояться, а необходимо рисковать и действовать смело. У этой пословицы есть китайский аналог «Не забравшись в логово тигра, не поймаешь тигренка», который передает такое же значение и употребляется в той же ситуации. Разница между ними заключается в образах «волк» и «тигр». Китайский аналог позволил бы читателю понять смысл речи собеседников, но выше пословица переведена дословно «Если $\mathrm{mbl}$ боишься волков, то не ходи в лес». При этом было добавлено выражение 我也听到过这样的俗话 (дословно: «Я слышала о такой пословице»). Оно подсказывает, что в речи имеется какая-то пословица. Так читатель может попытаться угадать ее переносное значение через дословный перевод. Но это может вызвать у него ложную ассоциацию. Таким образом, при переводе китайский аналог оказался более уместным.

Третья пословица «под лежачий камень вода не течет» также была переведена дословно. В результате смысл текста непонятен, образность теряется. Если мы используем китайский эквивалент «По дороге не пойдешь - не дойдешь, в колокол не ударишь - не зазвенит», то все становится понятнее.

\section{Пословицы, которые имеют более одного эквивалента в китайском языке}

\section{Что посеешь, то и пожнешь.}

Толкование: За свои (обычно неблаговидные) поступки, дела приходится расплачиваться. Говорится во время неудач, несчастий, являющихся результатом плохого поведения, поступка [14, с. 359]. 
Прагматика: используется в качестве предупреждения об опасности последствий принимаемого кем-либо решения либо при злорадном одобрении таких последствий как закономерных.

Данная пословица имеет три эквивалента в китайском языке:

1) 种瓜得瓜, 种豆得豆 (дословный перевод: «посеешь тыкву - соберешь тыкву, посеешь бобы получищь бобы»);

2) 一份耕耘, 一份收获 (дословный перевод: «как вспашешь землю, такой и урожай соберешь»);

3) 自作自受 (дословный перевод: «сам натворил, сам и отвечай»).

Все эти единицы имеют общее свойство, сообщают о результате поступка. Но у них есть отличия. У первой пословицы нейтральное значение. А во второй единице акцент делается на труде, часто говорится о работе и учебе. Третья единица имеет лишь отрицательное значение, часто используется с упреком или осуждением.

- Я пришел вам сказать, - сестра очень больна. Она скоро умрет, - добавил я глухо. - Что ж? - вздохнул отец, снимая очки и кладя их на стол. - Что посеешь, то и пожнешь. Что посеешь, - повторил он, вставая из-за стола, - то и пожнешь. (А. Чехов. Моя жизнь)

В этом диалоге сын пришел сообщить отцу, что сестра, с которой отец был в разладе, скоро умрет, побуждая его простить ее и встретиться с ней. Отец ответил половицей «Что посеешь, то и пожнешь», которая используется в данной ситуации как косвенный речевой акт отказа от встречи, отказа простить ее.

“是啊，”父亲叹道，摘下眼睛，把它放在桌子 上，“你种什么就收什么。你种什么，”他又说了一 遍，离开书桌站起来，“就收什么(http://99csw.com/ book/1804/50473.htm)

На китайский язык выражение было переведено дословно: «Что ты посеешь, то и получишь». Прочитав эту фразу, читателю легко ассоциировать ее со знакомой китайской пословицей “种瓜得瓜, 种豆得 豆” (дословный перевод: «посеешь тыкву - соберешь тыкву, посеешь бобы - получишь бобы»). При этом можно догадаться о том, что хочет сказать персонаж в контексте. Но мы считаем, что это все равно уступает китайскому эквиваленту. В переводе утрачена выразительность пословицы. Из трех эквивалентов “自作自受” (дословный перевод: «сам натворил, сам и отвечай») лучше всего передает психологическое состояние и эмоциональную окраску говорящего. В этой ситуации мы считаем это самым подходящим вариантом.

Итак, в большинстве случаев при наличии в языке перевода пословицы предпочтительным представляется перевод пословицы пословицей.

\section{Анализ русских пословиц, не имеющих эквивалента в китайском языке}

В русском языке есть пословицы, которые не имеют эквивалента в китайском языке. Эти пословицы в наибольшей степени отражают особенность менталитета народа данного языка. Например, «Береги платье снову, а честь смолоду» употребляется в современной русской речи, чтобы подчеркнуть, что все совершенные человеком действия формируют его репутацию в обществе. «Русский медленно запрягает, да быстро едет» говорит об одной из черт характера русских (неторопливость в начале какой-либо деятельности). Чтобы точно передать их значение и цель говорящего в тексте, переводчик либо использует толкование пословицы, либо создает свой вариант, опираясь на основное значение единиц.

\section{Любишь кататься, люби и саночки возить.}

Толкование: Неизбежно приходится расплачиваться за то, что было сделано с охотой, с удовольствием [14, с. 165$]$.

Прагматика: данная пословица часто употребляется в ситуации, где нужно взять ответственность за свои поступки, а также понять причинно-следственную связь.

Рассмотрим три варианта перевода пословицы «Любишь кататься, люби и саночки возить» из отрывка в произведении Л. Толстого «Анна Каренина».

- Bы сходите, сударь, повинитесь еще. Авось Бог даст. Очень мучаются, и смотреть жалости, да и все в доме навынтараты пошло. Детей, сударь, пожалеть надо. Повинитесь, сударь. Что делать! Люби кататься... (Л. Толстой. Анна Каренина)

Пословица используется как аргумент при побуждении к действию. Автор текста исходил из того, что пословица общеизвестна и использовал только ее первую часть.

1) 该可怜可怜孩子们, 老爷。认个错吧, 老爷。有什 么法子! 爱坐雪㲔.......”（陕西人民出版社，勒戈 译, 1997) (https://www.doc88.com/p-9962545090259. html);

2) 老爷, 您该怜悯怜悯孩子们。认个错吧, 老 爷。这是没有办法的! 要图快活, 就只好......” (http:// www.shijiemingzhu.cn/shijiemingzhu/anklnn/ 1448. html)

3) 老爷，你得可怜可怜孩子他们哪。去认个错 吧, 老爷。有什么办法呢! 玩出事情来了...”（上海 译文出版社, 草婴译, 1989) (https://www.sogou. com/link?url=DSOYnZeCC_orOCecstjRvMBDoLlUvk HH65ilCcKFNCURGih9r5_G3a4to0wa_Tif).

Пословица «Любишь кататься, люби и саночки возить» была переведена в следующих трех вариантах:

1) 爱坐雪榗 буквально означает «Любишь кататься на санях...»;

2) 要图快活, 就只好буквально означает «Раз любишь развлекаться, то...»; 
3) 玩出事情来了буквально означает «Bom mo, что вы натворили».

Как мы видим, первые два перевода представляют собой незаконченную фразу. В этом варианте пословица была переведена дословно. Образный компонент «саночки» сохранился, но значение и функция единицы не переданы. У китайского читателя возникает недоумение, ведь текст не касается санок.

Во втором переводе передан смысл, но переведенная фраза не является пословицей, поэтому данный вариант не идеален.

Третий вариант неверно передал эмоциональную окраску речи говорящего и даже исказил оригинальное значение. В переводе прослеживается интонация упрека, хотя в оригинале говорящий находится на стороне адресата.

Представляется, в таком случае лучше использовать описательный способ, т. е. толкование пословицы: Если хочешь развлекаться, то нужно за это заплатить, что-то отдать. Можно также попробовать дать образный описательный вариант, предварив его оборотом, вводящим пословицу: Как говорится в пословице, если любишь кататься с горки на санках, люби и поднимать их наверх.

\section{Заключение}

Мы рассмотрели основные проблемы перевода пословиц с русского языка на китайский. Мы убедились, что не у всех пословиц есть полный эквивалент в иностранных языках, поэтому каждый раз приходится переводить одну и ту же пословицу по-разному.

Для того чтобы решить эту проблему, в работе мы изучили пять видов перевода пословиц. При анализе примеров можно прийти к выводу о том, что у многих русских пословиц есть эквивалент в китайском языке, даже у некоторых есть более одного. Когда у пословицы есть эквивалент, особенно полный, то при переводе лучше использовать его. Частичный эквивалент не всегда оказывается уместным, ведь образные компоненты часто утрачиваются, но иногда можно использовать псевдопословичное соответствие. Переводчик должен сам изобрести новую пословицу, которая позволит максимально передать семантику, прагматику и сохранить образы в оригинале.

При сопоставлении всех видов перевода пословицы можно заметить, что при дословном переводе текст либо остается непонятным, либо значение искажается. Иногда это вызывает у читателей ложную ассоциацию. Поэтому он является самым ненадежным способом перевода пословицы. Причина в том, что образность ценится меньше, чем семантика пословицы. Представляется целесообразным пожерт- вовать образностью при переводе. Если же она важна для понимания текста, то всегда можно прибегнуть к культурным комментариям внизу страницы.

Когда отсутствует эквивалент пословицы, то необходимо определить значение единиц в контексте и найти наилучший вариант. Одним словом, перевод пословиц - это всегда нелегкая задача, важно учитывать все способы их перевода, выбирать то, что необходимо в зависимости от конкретного случая, чтобы точно и верно передать значение, эффективность и цель высказывания.

\section{ЛИТЕРАТУРА}

1. Arora, Shirley L. Proverbs and Prejudicr: EL Indio in Hispanic Proverbial Speech // Proverbium: Yearbook of international Proverb Scholfrship. 1994. Vol. 11. Pp. 27-46.

2. Верещагин Е. М., Костомаров В. Г. Язык и культура. Три лингвострановедческие концепции : лексического фона, речеповеденческих тактик и сапиентемы / под ред. и с послесл. акад. Ю. С. Степанова. М. : Индрик, 2005. $1040 \mathrm{c}$.

3. Рыбин П. В. Теория перевода : курс лекций для студентов IV курса дневного отделения. М., 2007. С. 7.

4. Бархударов Л. С. Язык и перевод. М., 1975.

5. Швейцер А. Теория перевода. М., 1988. 212 с.

6. Виноградов В. С. Введение в переводоведение. М. : Изд-во ин-та общ. сред. образования РАО, 2001. 224 c. URL: https://docplayer.ru/25941827-81-7-v-svinogradov-bbk-81-7.html

7. Пермяков Г. Л. Основы структурной паремиологии. М. : Наука, 1988.

8. Крикманн A. A. Некоторые аспекты семантической неопределенности пословицы / сост., ред. и предисл. Г. Л. Пермякова. М. : Наука, 1978. С. 82-104.

9. Фролова О. Е. Мир, стоящий за текстом. М. : ЛКИ, 2007. $320 \mathrm{c}$.

10. Шаронов И. А. Русские пословицы в диалоге : дискурсивно-прагматический подход к описанию // Актуальные проблемы и перспективы русистики : материалы по итогам Междунар. конф. русистов в Барселонском университете, МКР-Барселона, 19-23 июня 2018 г. Барселона, 2018. С. 1590-1597.

11. Fairclough N. Analysing Discourse. New York : Routledge, 2003.

12. Леонтович $O$. А. Методы коммуникативных исследований. М. : Гнозис, 2011.

13. Шаронов И. А., Ван Мэн. Прагматическое описание русских пословиц с двойным инфинитивом. «Московский лингвистический журнал», № 21 // Вестник РГГУ. Серия «Литературоведение. Языкознание. Культурология». 2019. № 7. С. 83-100.

14. Жуков В. П. Словарь русских пословиц и поговорок. М., 2000.

15. Ожегов С. И. Толковый словарь русского языка. URL: https://gufo.me/dict/ozhegov/век 


\section{REFERENCES}

1. Arora, Shirley L. Proverbs and Prejudicr: EL Indio in Hispanic Proverbial Speech // Proverbium: Yearbook of international Proverb Scholfrship. 1994. Vol. 11. Pp. 27-46.

2. Vereshhagin E. M., Kostomarov V. G. Yazyk i kultura. Tri lingvostranovedcheskie koncepcii: leksicheskogo fona, rechepovedencheskix taktik i sapientemy / Pod redakciej i s poslesloviem akademika Yu. S. Stepanova. M.: Indrik, 2005. $1040 \mathrm{~s}$.

3. Rybin P. V. Teoriya perevoda. Kurs lekcij dlya studentov IV kursa dnevnogo otdeleniya. M., 2007. P. 7.

4. Barxudorov L. S. Yazyk i perevod. M., 1975.

5. Shvejcer A. Teoriya perevoda. M., 1988. 212 p.

6. Vinogradov V. S. Vvedenie v perevodovedenie. M.: Izd-vo in-ta obshh. sred. obrazovaniya RAO, 2001. 224 p. Available at: https://docplayer.ru/25941827-81-7-v-svinogradov-bbk-81-7.html

7. Permyakov G. L. Osnovy strukturnoj paremiologii. M.: Nauka, 1988.

8. Krikmann A. A. Nekotorye aspekty semanticheskoj neopredelennosti poslovicy. Sost., red. i predisl. G. L. Permyakova. M.: Nauka, 1978. Pp. 82-104.

Российский государственный гуманитарный университет

Ван Мэн, аспирант кафедры русского языка

E-mail: marinawangmeng@mail.ru

Поступила в редакциюю 12 мая 2020 г.

Принята к публикаичи 25 сентября 2020 г.

\section{Для циитирования:}

Ван Мэн. Проблема перевода русских пословиц на китайский язык (на материале классических произведений) // Вестник Воронежского государственного университета. Серия: Лингвистика и межкультурная коммуникация. 2020. № 4. C. 58-65. DOI: https://doi. org/10.17308/lic.2020.4/3080
9. Frolova O. E. Mir, stoyashchij za tekstom. M., LKI, 2007. 320 p.

10. Sharonov I. A. Russkie poslovicy v dialoge: diskursivno-pragmaticheskij podxod $\mathrm{k}$ opisaniyu. In: Aktualnye problemy i perspektivy rusistiki. Materialy po itogam Mezhdunarodnoj konferenciya rusistov $\mathrm{v}$ Barselonskom universitete, MKR-Barselona, 19-23 iyunya. 2018. Barselona, 2018. Pp. 1590-1597.

11. Fairclough N. Analysing Discourse. New York: Routledge, 2003.

12. Leontovich O. A. Metody kommunikativnyh issledovanij. M.: Gnozis, 2011.

Sharonov I. A., Van Men. Pragmaticheskoe opisanie russkix poslovicz s dvojnym infinitivom. "Moskovskij lingvisticheskij zhurnal”, № 21. In: Vestnik RGGU, Seriya "Literaturovedenie. Yazykoznanie. Kulturologiya”. 2019. No. 7. Pp. 83-100.

13. Zhukov V. P. Slovar russkix poslovicz i pogovorok. M., 2000.

14. Ozhegov S. I. Tolkovyj slovar russkogo jazyka. Available at: https://gufo.me/dict/ozhegov/век

Russian State University For The Humanities

Wang Meng, Post-graduate Student of the Russian Language Department

E-mail: marinawangmeng@mail.ru

Received: 12 May 2020

Accepted: 25 September 2020

\section{For citation:}

Wang Meng. The problem of translating Russian proverbs into Chinese (on the example of classical works). Proceedings of Voronezh State University. Series: Linguistics and Intercultural Communication. 2020. No. 4. Pp. 58-65. DOI: https://doi.org/10.17308/lic.2020.4/3080 